\title{
Difficulty and familiarity norms for 192 single-solution word fragments
}

\author{
JAMES R. ERICKSON, CAROL RENAUD GAFFNEY, and WENDY P. HEATH \\ University of Texas at Arlington, Arlington, Texas
}

\begin{abstract}
Normative data are presented for the probability of successfully completing 192 single-solution word fragments. Normative data on the familiarity of college students with the solution words are also given, along with estimates of word frequency from existing norms. Regression analyses were performed in order to predict fragment completion difficulty from familiarity, frequency, and several structural characteristics of the fragments. Familiarity, whether or not first and/or last letters appeared in the fragment, and the ratio of letters to missing letters in the fragment were included in the regression equation as significant predictors of difficulty for this fragment set.
\end{abstract}

In a fragment completion test, an experimental subject is presented with a number of word fragments (e.g., B__K) and is asked to fill in the missing letters to form a word. Such tests have been used as alternatives to traditional memory tests, such as recognition or recall, and are of some interest because quite often performance functions are different for fragment completion than they are for other tasks. For example, it has been shown that although performance of amnesic patients is much worse than that of normal subjects on recognition or recall, the performance of amnesics and normals is similar in fragment completion (e.g., Graf \& Schacter, 1985; Graf, Squire, \& Mandler, 1984; Jacoby \& Witherspoon, 1982; Squire, Shimamura, \& Graf, 1985; Warrington \& Weiskrantz, 1970, 1974). For both kinds of subjects, prior exposure to words increases fragment completion performance for those words, but amnesic subjects do not recognize that they have been exposed previously to these words. Dissociations such as the one found between fragment completion and other memory tasks have aroused a good deal of theoretical and practical interest (e.g., Cohen, 1984; Squire, 1986; Tulving, 1983, 1985).

Most researchers who have used fragment completion as a task have used short common words and multiplesolution fragments, such as $\mathrm{C}_{--}$or $\mathrm{B}_{-} \mathrm{K}$. When the word book is presented as part of a study list, the probability that the fragment $\mathrm{B}_{-} \_\mathrm{K}$ will be completed as book increases. In other words, the most common dependent variable in fragment completion tasks has been the extent to which prior exposure biases the way in which a fragment is completed.

Tulving, Schacter, and Stark (1982) reported a dissociation involving fragment completion and recognition in normal subjects; recognition performance declined over a 1week delay period, whereas fragment completion performance remained almost constant. Tulving et al. (1982)

\footnotetext{
We wish to thank Scott Jones for assistance in data collection. Correspondence concerning this article should be sent to James R. Erickson, Department of Psychology, Box 19528, University of Texas at Arlington, Arlington, TX 76019.
}

used rather infrequent words and constructed the fragments so that only one word could be formed from each fragment. For example, one of their fragments was _R_U_IE_, from which one word can be formed (croupier). With fragments such as these, the dependent variable becomes the probability of solution, not the probability of a particular completion, and the task seems more like problem solving than word selection.

Previous research on the fragment completion task (e.g., Nelson, Canas, Bajo, \& Keelean, in press; Nelson \& McEvoy, 1984) has heavily stressed completion choice. One purpose of the present research was to supply normative information on the difficulty of one-solution fragments, since so little is known about performance on this task. The word fragments used by Tulving et al. (1982) were used because they are readily available, and it seems likely that researchers will be interested in using them.

Because the word list used by Tulving et al. (1982) contains many rather infrequent words, some of which may not even be known by many subjects, it also seemed useful to collect normative data on students' familiarity with these words. Familiarity ratings were obtained from students by asking them to rate each of the 192 words used by Tulving et al. (1982) on a 7-point familiarity scale. In addition, estimates of frequency of use of the words were obtained from the norms of Kučera and Francis (1967).

Fragment completion difficulty was estimated from the data of Erickson and Gaffney (1987) and from subjects whom we asked to complete word fragments as a filler task in experiments unrelated to fragment completion. Probability of successful completion of a fragment on the first exposure to it is the index of difficulty.

A secondary purpose of this research was to relate fragment completion difficulty to a variety of characteristics of the fragments and of the solution words. Regression analyses were performed to determine the extent to which completion difficulty could be predicted from the variables noted above along with several structural characteristics of the fragments. 


\section{METHOD}

\section{Subjects}

Subjects were students from the introductory psychology subject pool at the University of Texas at Arlington. These students volunteer for particular experiments to satisfy a course requirement, or they may choose to write summaries of published experiments if they do not wish to participate in experiments. A total of 80 subjects rated all 192 words for familiarity, and a number of other subjects provided difficulty data for various subsets of the word fragments.

\section{Materials and Procedure}

In order to obtain familiarity data, the 192 words used by Tulving et al. (1982) were randomly ordered and typed on four response sheets, with two columns of 25 words per page; 8 common words were added to the list to provide the same number of words per page and to add a number of words to the list as high-familiarity anchors. At the top of each page was a scale from 1 to 7 , with 1 representing low familiarity and 7 high familiarity. Raters were instructed to judge each word for familiarity, which was described as "how commonly or frequently [the words] have been experienced or how familiar they appear to be." The word person was used as an example of a highly familiar word, and the word amorphous was used as an example of a relatively unfamiliar one. Raters were encouraged to use the entire 7-point scale, but were not instructed about how often any particular rating should be used.

Difficulty data came from Experiments 1, 2, and 3 of Erickson and Gaffney (1987) and from subjects in unrelated experiments who were asked to complete word fragments as a filler task. Difficulty was defined as the proportion of subjects who successfully completed a fragment with no prior exposure to the fragment or the word represented by the fragment within the experimental setting. Due to the vagaries of random assignment of words to conditions in the various experiments, difficulty for different fragments was estimated by different numbers of subjects, ranging from 96 to 180 subjects per fragment. ${ }^{1}$

\section{RESULTS}

The basic data are presented in the Appendix, which gives each fragment, its solution word, the familiarity rating, the Kučera-Francis (1967) frequency, and the proportion of subjects who successfully completed the fragment.

We found that several of the items are not singlesolution fragments as intended by Tulving et al. (1982); other solutions given by our subjects are noted, along with their probabilities. In some cases, the alternative solutions were more popular with our subjects than were the in tended solutions (e.g., glasses and classes instead of chassis for ___ASS_S).

Subjects were reasonably familiar with most of the words in the list; the mean and median familiarity rat- ings were 5.19 and 5.78, respectively. However, the familiarity distribution is highly skewed, with a number of very unfamiliar words. For example, every one of the raters rated the word mazurka a 1 , or very unfamiliar; abattoir and Madeira are other examples of very unfamiliar words. A glance at the frequencies shows that the words on the list are very infrequent in the language, with a modal frequency of 0 and a median of 1 in the Kučera-Francis norms (the mean frequency was 4.47).

The fragments were very difficult to complete; the mean and median probabilities of completing a fragment were .13 and .07 , respectively. Twenty-three of the fragments were not completed correctly on first exposure by any of our subjects. The easiest fragment was $\mathrm{TW}_{-} \mathrm{I}_{-} \mathrm{T}$, completed correctly by $84 \%$ of the subjects. The distribution of completion difficulty is highly skewed. The 15 fragments completed by more than $43 \%$ of the subjects all fall above the outlier criterion suggested by Tukey (1977) (i.e., more than 1.5 times the interquartile range above the third quartile of the distribution); there were no high-difficulty outliers.

It should be noted that probability of completion of these fragments by our subjects is considerably lower than that found by Tulving et al. (1982); the probability of completing a new fragment in their experiment was about .30 . The difference in average fragment completion difficulty between our and Tulving et al.'s subject populations may simply reflect differences in subject populations or cultures, but it is large enough to be noteworthy.

We performed regression analyses to explore the extent to which frequency, familiarity, and several fragment structural variables could predict the probability with which a fragment was correctly completed. The structural variables selected are somewhat arbitrary, but they represent factors that seemed apt to be related to difficulty on a priori grounds. The following structural variables were calculated for each fragment:

F1: length of the word to be completed.

F2: 0 if neither the first nor last letter was present in the fragment, 1 if one of them was, 2 if both were present.

F3: maximum number of successive blanks in the fragment.

F4: maximum number of successive letters in the fragment.

F5: ratio of letters to blanks in the fragment.

F6: difference between number of letters and number of blanks in the fragment.

Table 1 shows the correlation matrix for these structural variables and the other variables discussed above. The variables that correlated significantly with fragment completion difficulty were familiarity, whether or not the first and/or last letters appeared in the fragment, and the ratio (or difference) between letters and blanks in the fragment. Since these latter two variables were so highly correlated, only F5 was included in the regression analyses.

Regression analyses were performed in order to predict 
Table 1

Intercorrelations Among Several Fragment and Fragment-Word

Characteristics, and Their Correlations with the Probability of Correctly Completing the Word Fragment

\begin{tabular}{lrrrrrrrr}
\hline & $p$ (corr.) & Familiarity & Frequency & F1 & F2 & F3 & F4 & F5 \\
\hline Familiarity & .381 & & & & & & & \\
Frequency & .111 & .256 & & & & & & \\
F1 & -.153 & .086 & -.023 & & & & & \\
F2 & .331 & -.016 & .089 & -.133 & & & & \\
F3 & .027 & .001 & .002 & .316 & .375 & & & \\
F4 & -.056 & -.088 & -.006 & -.070 & -.325 & -.089 & & \\
F5 & .279 & -.088 & .102 & -.511 & .275 & -.487 & .258 & \\
F6 & .213 & -.096 & .096 & -.445 & .287 & -.498 & .258 & .943 \\
\hline
\end{tabular}

Note-See the text for definitions of F1 to F6. Correlations greater in absolute value than .16 are significant beyond the .05 level.

difficulty for the 192 fragments. First, a stepwise analysis was performed, and a regression equation was calculated for the variables suggested by the stepwise analysis. In this analysis, familiarity, F2, and F5, in that order, chosen as a result of the forward stepwise procedure, with a statistically significant multiple $R^{2}$ of .31 . The resulting regression equation was:

$$
\begin{aligned}
p(\text { corr. }) & =-.3028+.0376 \text { Familiarity }+.0663 \mathrm{~F} 2 \\
& +.1400 \mathrm{~F} 5 .
\end{aligned}
$$

Although the difficulty of several fragments was not predicted well by this equation, there were no highleverage outliers. In every case, the fragments not fit well by the equation (fragments with high Studentized residuals) were relatively easy, being completed by over $50 \%$ of the subjects.

\section{DISCUSSION}

The results of the regression analyses are not particularly surprising; for fragments that contain first and last letters, the word search process should be easier (e.g., Nelson et al., in press), and having fewer blanks in the fragment would rather obviously influence difficulty. Also, of course, if subjects are not familiar with a word, they are not apt to use it to complete a word fragment. At least some of the variables that did not enter into the equation above would be expected to be related to fragment completion for other word sets. For example, the ranges of frequency, word length, and maximum successive blanks are all rather restricted in this word fragment set.

The fragment completion difficulties and word familiarities reported here should be of use in future research by experimenters wishing to manipulate or control for difficulty or familiarity, or by those wishing to use them as covariates in data analysis.

\section{REFERENCES}

COHEN, N. J. (1984). Preserved learning capacity in amnesia: Evidence for multiple memory systems. In L. Squire \& N. Butters (Eds.), The neuropsychology of memory. New York: Guilford Press.
Erickson, J. R., \& GAFFney, C. R. (1987). Relations between fragment completion and recognition memory. Manuscript submitted for publication.

Graf, P., \& Schacter, D. L. (1985). Implicit and explicit memory for new associations in normal and amnesic subjects. Journal of Experimental Psychology: Learning, Memory, \& Cognition, 11, 501-518.

Graf, P., Squtre, L., \& Mandler, G. (1984). The information that amnesic patients do not forget. Joumal of Experimental Psychology: Learning. Memory, \& Cognition, 10, 164-178.

JACOBY, L. L., \& WITHERSPOON, D. (1982). Remembering without awareness. Canadian Journal of Psychology, 32, 300-324

KUČERA, M., \& FRANCIS, W. (1967). Computational analysis of presentday American English. Providence, RI: Brown University Press.

Nelson, D. L., Canas, J. J., Bajo, M., \& Keelean, P. D. (in press). Comparing word fragment completion and cued-recall with letter cues. Journal of Experimental Psychology: Leaming, Memory, \& Cognition.

Nelson, D. L., \& McEvoy, C. L. (1984). Word fragments as retrieval cues: Letter generation or search through nonsemantic memory? American Journal of Psychology, 97, 17-36.

Squire, L. R. (1986). Mechanisms of memory. Science, 232, 1612-1619.

Squire, L. R., Shimamura, A. P., \& Graf, P. (1985). Independence of recognition memory and priming effects: A neuropsychological analysis. Joumal of Experimental Psychology: Learning, Memory, \& Cognition, 11, 37-44.

TUKEY, J. W. (1977). Exploratory data analysis. Reading, MA: Addison-Wesley.

Tulving, E. (1983). Elements of episodic memory. New York: Oxford University Press.

Tulving, E. (1985). How many memory systems are there? American Psychologist, 40, 385-398.

Tulving, E., Schacter, D. L., \& Stark, H. A. (1982). Priming effects in word-fragment completion are independent of recognition memory. Journal of Experimental Psychology: Learning, Memory, \& Cognition, 8, 336-341.

Warrington, E. K., \& Weiskrantz, L. (1970). The amnesic syndrome: Consolidation or retrieval? Nature, 228, 628-630.

Warrington, E. K., \& Weiskrantz, L. (1974). The effect of prior learning on subsequent retention in amnesic patients. Neuropsychologia, 12, 419-428.

\section{NOTE}

1. Word fragments are extremely difficult to proofread. Because of proofreading errors, seven of the word fragments used here differed from those used by Tulving et al. (1982), and the sample sizes from which fragment difficulties were estimated were quite small $(n=22)$ for three fragments. These fragments are noted in the table of fragment difficulties in the Appendix. 
APPENDIX

Familiarity Ratings, Normative Frequency, and Difficulty for 192 Single-Solution Word Fragments

\begin{tabular}{|c|c|c|c|c|}
\hline Fragment & Word & Familiarity & Frequency & $p$ (Completion) \\
\hline AR_VA_- & $\begin{array}{l}\text { aardvark } \\
\text { caravans (.11) }\end{array}$ & 6.21 & 0 & .09 \\
\hline A__ $\mathbf{T} \_\mathbf{I R}$ & abattoir & 1.05 & $\mathbf{0}$ & 0 \\
\hline $\mathrm{AD}_{-} \_\mathrm{D}^{*}$ & $\begin{array}{l}\text { adenoid } \\
\text { admired (.03) } \\
\text { adopted (.02) } \\
\text { advised (.02) } \\
\text { adhered }(.01)\end{array}$ & 3.53 & $\mathbf{0}$ & .01 \\
\hline $\mathrm{AF}_{--} \mathbf{N I}$ & afghani & 2.90 & 0 & 0 \\
\hline _G_O_T_C & agnostic & 3.90 & 0 & .05 \\
\hline AI__P_CE & airspace & 6.70 & 0 & .14 \\
\hline $\mathrm{AL} \quad \mathrm{RY}$ & allegory & 3.72 & 3 & .20 \\
\hline AL__N_C & almanac & 6.50 & 1 & .39 \\
\hline AN____UE & analogue & 3.48 & 1 & .01 \\
\hline $\mathrm{AN}_{-\_-} \mathrm{MY}$ & anatomy & 6.86 & 9 & .55 \\
\hline _N_NNA & antenna & 6.90 & 13 & .10 \\
\hline A__IDO_- & antidote & 6.55 & 2 & .02 \\
\hline $\mathrm{AN}_{-}$_UE & antique & 6.78 & 12 & .04 \\
\hline $\mathrm{AN}_{-} \mathrm{DY}$ & anybody & 7.00 & 42 & .04 \\
\hline AP_O_B & aplomb & 1.37 & 1 & .15 \\
\hline APP__AL & $\begin{array}{l}\text { approval } \\
\text { appeasal }(.01)\end{array}$ & 7.00 & 51 & .28 \\
\hline AP___OT & apricot & 6.92 & 1 & .53 \\
\hline AR___ & archduke & 5.15 & 0 & .09 \\
\hline -SB___ $\mathrm{O}_{-}$ & asbestos & 6.23 & 1 & .03 \\
\hline A__ A__IN & assassin & 6.61 & 6 & .02 \\
\hline AT___IT & atrocity & 4.53 & 0 & .01 \\
\hline $\mathrm{V}_{-} \mathrm{AD}_{-}$ & avocado & 6.95 & 11 & .06 \\
\hline BA__E_OR & bachelor & 7.00 & 6 & .64 \\
\hline _A_D_NNA* & bandanna & 6.95 & $\mathbf{0}$ & .06 \\
\hline $\mathrm{BA} \quad \mathrm{CA}$ & basilica & 1.87 & $\mathbf{0}$ & 0 \\
\hline B_S_OO_ & bassoon & 5.53 & $\mathbf{0}$ & .19 \\
\hline __YO_ET & bayonet & 6.51 & 6 & .04 \\
\hline B_Z_O_- & bazooka & 6.80 & 0 & .26 \\
\hline __ES__ X & beeswax & 6.41 & 0 & .02 \\
\hline _EG_NI_ & begonia & 4.56 & 0 & .01 \\
\hline $\mathrm{BE}_{--} \mathrm{VI}_{--}$ & behavior & 6.95 & 96 & .25 \\
\hline B_ DDE & bladder & 6.78 & 0 & .16 \\
\hline _L_RNE_ & blarney & 3.50 & 0 & .03 \\
\hline _OG_Y & bogeyman & 5.76 & 0 & $\mathbf{0}$ \\
\hline _O__UGH & borough & 4.62 & 5 & .15 \\
\hline$\ldots \mathrm{SCH}_{-}$ & $\begin{array}{l}\text { borscht } \\
\text { Porsche (.04) }\end{array}$ & 1.84 & 0 & .01 \\
\hline _OU__ON & $\begin{array}{l}\text { bourbon } \\
\text { Houston (.02) }\end{array}$ & 6.82 & 8 & .03 \\
\hline$-\mathrm{OYH} \_\mathrm{O}_{-}$ & boyhood & 6.95 & 5 & .23 \\
\hline BRA___N & brahmin & 1.39 & 0 & 0 \\
\hline BR__A_O & bravado & 3.83 & 7 & .14 \\
\hline B__ZI_R & brazier & 4.66 & 1 & .27 \\
\hline B__CC & broccoli & 6.92 & 1 & .09 \\
\hline BU_L__K & bullock & 2.14 & 2 & .21 \\
\hline BU_E_U & bureau & 6.66 & 43 & .35 \\
\hline C_AR_T & $\begin{array}{l}\text { cabaret } \\
\text { cigaret }(.04)\end{array}$ & 5.80 & 1 & .11 \\
\hline A_H_RE & cashmere & 6.13 & 2 & 0 \\
\hline C_VA__Y & cavalry & 6.75 & 26 & .36 \\
\hline
\end{tabular}


APPENDIX (Continued)

\begin{tabular}{|c|c|c|c|c|}
\hline Fragment & Word & Familiarity & Frequency & $p$ (Completion) \\
\hline _ASS_S & $\begin{array}{l}\text { chassis } \\
\text { glasses }(.22) \\
\text { classes }(.11) \\
\text { grasses }(.03) \\
\text { brasses }(.02)\end{array}$ & 4.50 & 1 & .02 \\
\hline C__CC_RY & chicory & 2.49 & 0 & .02 \\
\hline IMN_Y & chimney & 6.95 & 7 & .51 \\
\hline $\mathrm{CH}_{-}$ & chipmunk & 6.88 & 0 & .34 \\
\hline C_O___RA & cholera & 4.93 & 1 & .08 \\
\hline C_UTN & chutney & 1.80 & 1 & .05 \\
\hline _I__AMO_ & cinnamon & 7.00 & 0 & .01 \\
\hline $\mathrm{L} \_\mathrm{R} \quad \mathrm{ET}$ & clarinet & 6.78 & 1 & .21 \\
\hline _L_M_TE & climate & 6.83 & 26 & .07 \\
\hline $\mathrm{C}_{-} \mathrm{BLE}_{-}$ & cobbler & 6.48 & 0 & .12 \\
\hline $\mathrm{C} \quad \mathrm{T}_{-} \mathrm{O}$ & cockatoo & 5.78 & 1 & .02 \\
\hline O_O_UT & coconut & 6.98 & 7 & .11 \\
\hline C_NIF_ & conifer & 2.42 & 0 & .24 \\
\hline $\mathrm{CO}_{--} \mathrm{AT}$ & copycat & 6.76 & 0 & 0 \\
\hline $\mathrm{O}_{-} \mathrm{TE}$ & corvette & 7.00 & 0 & .34 \\
\hline OS & cossack & 3.05 & 3 & 0 \\
\hline REV_CE & crevice & 5.86 & 2 & .54 \\
\hline CRO_U & croquet & 6.08 & 0 & .15 \\
\hline _R_U_IE_ & croupier & 1.22 & 0 & 0 \\
\hline UP $\mathrm{KE}$ & cupcake & 6.98 & 0 & .22 \\
\hline $\mathrm{CU} \quad \mathrm{OR}$ & curator & 4.33 & 2 & .10 \\
\hline C_TL_RY* & cutlery & 5.13 & 0 & .70 \\
\hline Y ${ }_{-}{ }_{-} D_{-}$ & cyanide & 4.86 & 0 & 0 \\
\hline D_L_IIU_ & delirium & 5.55 & 3 & .06 \\
\hline M_C_AT & democrat & 6.86 & 13 & .28 \\
\hline D_N_SA & dinosaur & 6.98 & 1 & .38 \\
\hline _U_E_UM & duodenum & 3.30 & 0 & .02 \\
\hline EC_R_N & electron & 6.55 & 30 & .12 \\
\hline LL $P$ E & ellipse & 5.55 & 0 & .11 \\
\hline $\bar{E} \_$S_AR_ & emissary & 3.24 & 2 & .02 \\
\hline PI $\quad$ PH & epitaph & 4.76 & 4 & .18 \\
\hline S_R_S_O & espresso & 4.23 & 0 & .01 \\
\hline STU_R & estuary & 1.53 & 0 & .02 \\
\hline $\mathrm{X}_{-} \mathrm{O}_{-} \mathrm{NT}$ & exponent & 6.45 & 0 & .11 \\
\hline F C SM & fascism & 5.63 & 3 & .41 \\
\hline LT__TE & filtrate & 5.27 & 0 & .01 \\
\hline L_MI_G_ & flamingo & 6.78 & 0 & .04 \\
\hline $\bar{F} L \_-E L$ & flannel & 6.85 & 4 & .45 \\
\hline $\mathrm{G}_{-} \mathrm{GR} E$ & gangrene & 6.60 & 0 & .12 \\
\hline$-\bar{A} Z \_L \_\bar{E}$ & gazelle & 5.75 & 1 & .16 \\
\hline $\mathrm{AZ}$ TE & gazette & 6.28 & 10 & .20 \\
\hline I Z RD & gizzard & 6.61 & 0 & .18 \\
\hline G_DO_A & gondola & 6.10 & 0 & .24 \\
\hline G_A_RY & granary & 2.45 & 2 & .01 \\
\hline H_Y FT & hayloft & 6.86 & 0 & .41 \\
\hline $\bar{E} X_{-} \bar{G}_{-}$ & hexagon & 6.31 & 1 & .27 \\
\hline B SC $S$ & hibiscus & 4.60 & 0 & .09 \\
\hline $\mathrm{HO}$ & horizon & 6.95 & 27 & .03 \\
\hline & Houston (.26) & & & \\
\hline${ }_{-} \mathrm{YA} \_\mathrm{N} \_\mathrm{H}$ & hyacinth & 3.63 & 0 & .01 \\
\hline YD_AN & hydrant & 6.78 & 0 & .04 \\
\hline DEO_O & ideology & 5.61 & 13 & .16 \\
\hline IM_IB_- & imbiber & 1.42 & 0 & .08 \\
\hline$I_{C} \quad$ ON & incision & 6.76 & 0 & .01 \\
\hline NE T A & inertia & 5.08 & 2 & .01 \\
\hline I_F_CO & inferno & 6.85 & 2 & .18 \\
\hline IN_W_L_ & inkwell & 6.48 & 0 & .06 \\
\hline
\end{tabular}


APPENDIX (Continued)

\begin{tabular}{|c|c|c|c|c|}
\hline Fragment & Word & Familiarity & Frequency & $p$ (Completion) \\
\hline$\_\mathbf{N} \_$MN $\_$A & insomnia & 6.63 & 3 & .08 \\
\hline HM_S & isthmus & 3.67 & 0 & 0 \\
\hline J__ $\mathbf{M}_{---} \mathbf{E}$ & jamboree & 6.20 & 0 & .17 \\
\hline TY_I & katydid & 3.70 & 0 & 0 \\
\hline $\mathrm{K} \_-\mathrm{O} \_$NE & kerosene & 6.76 & 6 & .16 \\
\hline KN_P & knapsack & 6.60 & 0 & .33 \\
\hline$M Q \quad T$ & kumquat & 4.73 & 0 & .27 \\
\hline _AC_OS & lacrosse & 4.63 & 0 & .12 \\
\hline LA_Y_G & ladybug & 7.00 & 0 & .13 \\
\hline L_G_RD & laggard & 1.28 & 0 & .10 \\
\hline NO_IN & lanolin & 5.68 & 0 & .07 \\
\hline _CT_RN & lectern & 2.94 & 0 & .12 \\
\hline E__OSY & leprosy & 5.78 & 1 & .15 \\
\hline E_E_TUC_ & lettuce & 7.00 & 0 & .25 \\
\hline _EU__M_A & leukemia & 6.80 & 3 & .14 \\
\hline _EX_C_N $†$ & $\begin{array}{l}\text { lexicon } \\
\text { Mexican (.18) }\end{array}$ & 1.85 & 2 & 0 \\
\hline L_NE_E & lineage & 5.15 & 2 & .04 \\
\hline TH_UM & lithium & 3.30 & 0 & .17 \\
\hline _OZ__GE & lozenge & 5.23 & 0 & .07 \\
\hline D_IRA & Madeira & 1.18 & 1 & .02 \\
\hline JO_AM & marjoram & 1.60 & 0 & .01 \\
\hline RT __I & martini & 6.85 & 6 & .07 \\
\hline M_S_A_A & mascara & 6.73 & 1 & .01 \\
\hline M_Z_R_A & mazurka & 1.00 & 2 & .01 \\
\hline $\mathrm{MB}_{-} \mathrm{NE}$ & membrane & 6.70 & 6 & .16 \\
\hline M__T_OL & menthol & 6.53 & 0 & .25 \\
\hline IGR_N N & migraine & 6.75 & 0 & .11 \\
\hline MO_O__M & monogram & 6.75 & 0 & .08 \\
\hline _YS__RY & mystery & 6.92 & 39 & .20 \\
\hline _EO__TE & neonate & 1.24 & 0 & 0 \\
\hline I_VA A & nirvana & 1.30 & 1 & 0 \\
\hline NO___ $\mathrm{NE}$ & nocturne & 3.07 & 3 & .01 \\
\hline OB__I_K & obelisk & 1.55 & 6 & .03 \\
\hline O_T_US & octopus & 6.90 & 1 & .53 \\
\hline _P____TTA & operetta & 4.32 & 6 & .07 \\
\hline ORA__O_ & oration & 3.70 & 3 & .07 \\
\hline U S S ER & $\begin{array}{l}\text { outsider } \\
\text { consumer }(.01)\end{array}$ & 6.88 & 3 & 0 \\
\hline FF_N & paraffin & 5.51 & 0 & 0 \\
\hline _A__NO_A & paranoia & 6.20 & 0 & .05 \\
\hline _E_D_L_M & pendulum & 6.65 & 2 & .09 \\
\hline _ER_X____- ${ }^{*}$ & $\begin{array}{l}\text { peroxide } \\
\text { Xeroxing (.06) }\end{array}$ & 6.71 & 2 & .02 \\
\hline _E_UNI_ & petunia & 6.61 & 0 & .01 \\
\hline PH___OH & pharaoh & 6.26 & 0 & .14 \\
\hline P_EN_X & phoenix & 5.92 & 9 & .68 \\
\hline P_GM_T & pigment & 6.58 & 9 & .79 \\
\hline P_E_TO & pimento & 6.83 & 0 & .15 \\
\hline NK_ON & plankton & 5.16 & 0 & .19 \\
\hline PO__IW & polliwog & 4.23 & 0 & .01 \\
\hline _U_R_ET & quartet & 6.61 & 9 & .02 \\
\hline$\overline{\mathbf{R}}-\bar{B} \_\mathbf{W}$ & rainbow & 6.98 & 4 & .74 \\
\hline _AR_EE & repartee & 1.88 & 1 & .01 \\
\hline HE $\_$OR & rhetoric & 4.75 & 5 & .02 \\
\hline H_MB_S & rhombus & 3.87 & 0 & .01 \\
\hline HU____B & rhubarb & 6.55 & 0 & .06 \\
\hline RO_DA & rotunda & 4.98 & 6 & .10 \\
\hline _UFF_A_ $\dagger$ & ruffian & 4.80 & 2 & 0 \\
\hline U U_- B_GA & rutabaga & 5.18 & 1 & .08 \\
\hline A_SK_I_ & Sanskrit & 1.80 & 0 & .02 \\
\hline
\end{tabular}


APPENDIX (Continued)

\begin{tabular}{|c|c|c|c|c|}
\hline Fragment & Word & Familiarity & Frequency & $p$ (Completion) \\
\hline APP_I & sapphire & 6.86 & 0 & .01 \\
\hline $\mathrm{SC}_{-} \quad \mathrm{AR}$ & scimitar & 1.39 & 1 & .01 \\
\hline SE_O_A & sequoia & 4.07 & 2 & .05 \\
\hline EX_NT & sextant & 4.07 & 0 & .13 \\
\hline$S_{-} \quad F F$ & sheriff & 7.00 & 20 & .18 \\
\hline SI__C_N & silicon & 5.63 & 2 & .51 \\
\hline __RGHU & sorghum & 3.17 & 3 & .01 \\
\hline _P_TU_A & spatula & 6.73 & 0 & .17 \\
\hline _PI_T_E & $\begin{array}{l}\text { spittle } \\
\text { epistle }(.01)\end{array}$ & 3.17 & 2 & .03 \\
\hline PR__ET & sprocket & 5.78 & 0 & .01 \\
\hline SU_G__N & surgeon & 6.95 & 11 & .62 \\
\hline S_AH_I & Swahili & 3.80 & 1 & .05 \\
\hline$-\mathrm{AF}_{--} \mathrm{TA}$ & taffeta & 3.07 & 2 & .10 \\
\hline $\bar{T}$ __UI_A & tequila & 6.86 & 0 & .10 \\
\hline _H_O_EM & theorem & 5.28 & 18 & .04 \\
\hline YR_ID & thyroid & 6.28 & 38 & .07 \\
\hline _OB_GG & toboggan & 6.35 & 0 & .09 \\
\hline RI_Y & tricycle & 7.00 & 0 & .01 \\
\hline $\mathrm{TW} \quad \mathrm{I}-\mathrm{T}$ & twilight & 6.85 & 4 & .84 \\
\hline _NI__R_E & universe & 7.00 & 71 & .02 \\
\hline _R_-HR_ & urethra & 5.25 & 1 & 0 \\
\hline E_D_TT & vendetta & 5.03 & 0 & .02 \\
\hline V__A_D_H & verandah & 4.50 & 1 & .07 \\
\hline ___ UTH & vermouth & 5.06 & 1 & .02 \\
\hline CAR_E* & vicarage & 1.95 & 0 & 0 \\
\hline _IC_RO_ & viceroy & 4.87 & 1 & .01 \\
\hline $\bar{W}_{-} \quad \overline{N T Y}$ & warranty & 6.92 & 0 & .44 \\
\hline $\mathrm{AV}_{-} \mathrm{ET}$ & wavelet & 1.92 & 0 & 0 \\
\hline Y_o__NR_ & yeomanry & 1.37 & 0 & 0 \\
\hline O_HUR & yoghurt & 6.48 & 0 & 0 \\
\hline $\bar{Z}$ ___E_IN & zeppelin & 5.03 & 0 & .18 \\
\hline
\end{tabular}

Note-Alternative solutions and their probabilities are shown for fragments that turned out to have more than one solution. *Fragments different from those used by Tulving et al. (1982). †Fragments for which the difficulty estimates are based on small sample sizes.

(Manuscript received October 10, 1986;

revision accepted for publication April 13, 1987.) 